\title{
Gazing over the horizon Will an equitable Green Climate Fund allocation policy be significant for the Pacific post-2020?
}

\begin{abstract}
The establishment of the Green Climate Fund (GCF) has increased expectations and optimism among developing countries, especially those that are particularly vulnerable to climate change. The GCF aims to channel a significant portion of global funds for climate change response, with a goal of reaching US $\$ 100$ billion per year by 2020. Its broad allocation policy increases the possibility that particularly vulnerable countries which have struggled to access international climate finance will continue to face such challenges. Adopting an equitable/fair principle of allocation, this article highlights a number of scenarios on the possible impact of the post-2020 climate financing environment on particularly vulnerable countries with a special focus on the Pacific Small Island Developing States (PSIDS). This study argues that PSIDS are extremely sensitive to GCF allocation mechanisms. While the study supports the notion of balanced allocation as currently advanced by the GCF, the precarious situation of PSIDS necessitates a re-think of how the GCF finance is to be allocated in the future.
\end{abstract}

Keywords: climate change, climate finance, Green Climate Fund, Pacific Small Island Developing States

\section{JALE SAMUWAI and JEREMY MAXWELL HILLS The University of the South Pacific, Suva}

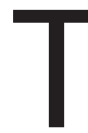

HE ESTABLISHMENT of the Green Climate Fund (GCF) in 2010 to mobilise climate finance to developing countries received a lot of fanfare and positive accolades from the world media and world leaders (Rowling, 2012, Azevedo, 2017). The GCF has been referred to as unique (Kumar 2017), a 'game changer' (Countries pledge \$9.3bn, 2014), the world's largest (Arkin, 2018) and premium multilateral climate fund (Friends of the Earth, 2014), and the primary channel which will deliver a significant portion of the 2020 , US $\$ 100$ billion global climate finance goal to developing countries. The GCF's purpose is to not only support country-owned, ambitious and innovative climate actions that will limit global emissions and enhance resilience of developing countries (GCF, 2018a; UNDP, 2018), but also to correct the 'inequality of 
climate finance distributions' that many developing countries have been arguing as being unfair (Harvey, 2014).

Donors have pledged an ambitious US $\$ 10.2$ billion to the GCF by 2018 and additional contributions are expected through the GCF to reach US $\$ 100$ billion by 2020 . The GCF has also been used as a platform by donor countries to showcase their global commitment to the fight against climate change, attracting showers of praise from developing countries and the media alike. Because of the ambitious cause that it advances and its promise of big money, the GCF has been portrayed and viewed by developing countries, especially the Pacific Small Island Developing States (PSIDS) as a 'timely saviour' for their climate finance needs (GCF, 2017). The GCF has to a larger extent been presented to developing countries as the solution to their climate change problem; an infinite source of climate finance. The GCF has become synonymous with the term climate finance.

However, a critical evaluation of the current GCF allocation policy has highlighted that such a portrayal does not withstand close inspection. While the resources directed to the GCF are substantial, there is concern that its current allocation policy, which advances a geographically balanced approach (GCF, 2014) may seriously disadvantage particularly vulnerable countries. Under the GCF, particularly vulnerable countries consist of the Least Developed Countries (LDCs), Small Island Developing States (SIDS) and Africa. Such open-ended allocation policies can further marginalise particularly vulnerable countries which have struggled to access predictable finance from multilateral climate funds. It does little to solve the current problem of the ad hoc, inadequate and donor-driven flow of climate finance into such countries. Sporadic inflows of finance further exacerbate countries' vulnerability and reduce their resilience to climate change (Maclellan, 2011). Effectively addressing climate change impacts will require long-term support, but such support cannot be planned or implemented without a degree of certainty about funding availability (Müller, 2013).

The need to bring the GCF allocation policies to the fore in public discourse stems from the race for accreditation ${ }^{1}$ that is underway among developing countries (Samuwai \& Hills, 2018). The perception of future big money flowing into the GCF has prompted developing countries to mobilise significant national resources to strengthen their institutional capacities so that they can gain accreditation with the GCF and directly access its resources by 2020 and beyond.

The uncertainty of the availability of funding underlines the importance for the GCF to start considering how well/best to allocate its funding in the future so that all developing countries will benefit and that no one will be left behind. The GCF is facing uncertainties in terms of its replenishment. At the current rate of projects approval (as of September 2018), the GCF is very close to triggering its first replenishment cycle but its 'chaotic' governance performance has been criticised by many donors as a potential hindrance to the scaling up of their future 
pledges. This uncertainty is exacerbated further by the withdrawal of the United States, a major global donor, from the Paris Agreement.

The uncertainties of GCF funding should be a major concern for particularly vulnerable countries which are actively seeking direct access to the GCF as the process of accessing the GCF is also challenging and complex (GCF, 2018b; Samuwai \& Hills, 2018). The recent independent review of the GCF readiness program has indicated that the programme has so far shown least effect to the particular vulnerable countries and also that direct access, despite being prioritised for such countries, has been limited (GCF, 2018b).

The challenges surrounding particularly vulnerable countries accessing the GCF funding is further complicated by the recent findings of the special report on global warming of $1.5^{\circ} \mathrm{C}$ by the Intergovernmental Panel on Climate Change (IPCC). The special report is clear that the consequences of $1.5^{\circ} \mathrm{C}$ warming (and over) would be extreme and existential for particularly vulnerable countries (IPCC, 2018). A 10 year window has been estimated before warming reaches the $1.5^{\circ} \mathrm{C}$ threshold (IPCC, 2018). Thus, in light of these alarming findings, facilitating ease of access to adequate and predictable climate finance from sources (including the GCF) for particular developing countries has never been greater.

\section{The Pacific situation}

Scattered over the largest ocean in the world, the PSIDS are at the front line of climate change (Robie \& Chand 2017), but their voice is absent from mainstream climate finance literature (Dreher \& Voyer 2015, Wing, 2017). Existing academic climate finance studies tend to aggregate the PSIDS' unique situations with those of the larger Asian countries in the Asia-Pacific region, resulting in the drowning of PSIDS voices (Maclellan, 2011). Without discounting the climate change realities of other particularly vulnerable countries, fair attention to the PSIDS climate finance needs is warranted because some PSIDS are now facing threats to their existence.

A total of 15 PSIDS - Cook Islands, Federated States of Micronesia (FSM), Fiji, Kiribati, the Marshall Islands, Nauru, Niue, Palau, Papua New Guinea (PNG), Samoa, the Solomon Islands, Timor-Leste, Tonga, Tuvalu and Vanuatu-have signed the United Nations Framework Convention on Climate Change (UNFCCC).

Accessing predictable and adequate adaptation finance is the priority of PSIDS, due to their topography. The amount of adaptation climate finance channelled to the PSIDS is relatively modest compared with that allocated to other developing countries and is largely ad hoc in nature (Durand, Schalatek et al., 2015, Atteridge \& Canales, 2017). Of the US $\$ 1.3$ billion allocated for the AsiaPacific region, only 4.6 percent was channelled to PSIDS (Barnard, Nakhooda et al., 2015). Bilateral agencies are the main sources of finance in the region. Accessing quality and predictable finance from multilateral climate funds is a 
constant challenge for the PSIDS due to their chronic capacity constraints. In addition, the total climate finance received is diluted as a significant portion of the amount ( $\sim 8$ percent to 20 percent) is deducted as management fees by international accredited entities such as the UNDP, World Bank and Asia Development Bank which accessed these funds on the PSIDS' behalf (Atteridge \& Canales, 2017).

Due to their very small population, PSIDS are regarded as the highest recipient of climate finance on a per capita basis. However, critics have argued that this fact can be misleading as it does not reflect PSIDS realities (Dirix, Peeters et al. 2012). PSIDS are scattered across 15 percent of the globe's surface and are some of the remotest countries from major global markets, making the mobilisation of climate finance challenging and very costly (The World Bank, 2017). PSIDS have not been able to access their fair share of climate finance, which has exacerbated their already extreme vulnerability (Maclellan, 2011a).

For its part, the GCF has ramped up its effort to mobilise climate finance to the PSIDS and is co-financing nine major projects in the Pacific, accounting for US\$296 million, which accounts for 8 percent of the GCF funding portfolio. However, it is still highly uncertain how the PSIDS will fare in future GCF disbursement cycles under a geographical balance allocation policy. There is great uncertainty as to whether PSIDS can continue to secure significant financing from the GCF in light of other developing countries' growing climate change needs. So far, only the Cook Islands, Fiji and Federated States of Micronesia are the PSIDS which have been accredited by the GCF for direct access.

The high degree of uncertainty over future funding access to the GCF should motivate the PSIDS to engage the GCF to initiate constructive discussions on the need for a concrete yet fair allocation policy to ensure predictable funding. In light of PSIDS circumstances, the ideal GCF allocation criteria would be one that resulted in predictable finance to meet the PSIDS' immediate and long-term needs (Maclellan \& Meads, 2016).

\section{Justification for equitable/fair allocation of adaptation finance}

According to the seminal work of John Rawls, fairness is synonymous with the concept of equity (Rawls, 1958). Thus, the push for equity as the basis of adaptation finance allocation is driven by the idea of 'restitution' - an obligation that needs to be settled as inferred by the polluter pay principle of the UNFCCC (Eisenack \& Stecker 2012). The absence of a robust allocation policy that takes care of special case countries like the PSIDS has resulted in the marginalisation of particularly vulnerable countries, underlying the importance of equitable processes within the financial mechanisms of the UNFCCC (Müller, 2013). The role of equity in climate finance allocation is critical, as noted by (Sokona \& Denton 2001), to 'assure that vulnerable people in the remotest outposts of the world do 
not become imprisoned in perennial cycles of destitution and impoverishment at the mercy of climate events' (p. 120). While equity might be a broad and politically sensitive concept, it is perceived as relevant in the policy discourse around the allocation of adaptation climate finance (Persson \& Remling 2014).

Equity has four general principles: 1) equality, 2) prioritarianism, 3) sufficientarianism and 4) the leximin principle (Persson \& Remling 2014). All equity principles have merits in the allocation of adaptation finance (Grasso, 2010), but this study identified only two as currently being operationalised by multilateral climate funds. These are: 1 ) the equality principle, which demands funds be equally distributed to all countries despite their different circumstances (Paavola \& Adger 2006), and 2) the prioritarianism principles, which prioritises funding for those that are worse affected by climate change; the most vulnerable (Wolff 1998, Stadelmann, Persson et al., 2014).

These two equity principles are prevalent in the allocation of adaptation finance and can be attributed to the different rationale of equity between developed (donors) and developing countries (recipients) (Maggioni, 2010). Maggioni (2010) argues that the equality principle reflects the argument of developed countries that there is a limit to resources that can be provided and thus, for fairness sake, all eligible countries should get an equal share. Müller (2013) provided further support, arguing that treating all eligible countries as equal, despite their circumstances, is politically justifiable as it ensures that funding is available to all.

The prioritarianism principle, on the other hand, champions developing countries' preference for channelling adaptation finance to those who really need it (Maggioni, 2010). Stadelmann, Persson et al. (2014) supported such a stance, stressing that a vulnerable country's needs should be prioritised and that they should be given the bulk of finance (Paavola \& Adger, 2006). These rationales are based on the unequal vulnerabilities and responsibilities of countries in terms of their contributions and sensitivity to climate change (Grasso, 2010).

Allocating finance on the basis of vulnerability has been strongly criticised as it is a political construct (Klein \& Möhner 2011, Füssel, Hallegate et al., 2012), is difficult to measure and compare (Stadelmann, Persson et al., 2014), and is subjective (Barnett, Lambert et al., 2008). Füssel, Hallegate et al., (2012), Müller (2013) and Ferreira (2017) have proposed various modified forms of 'vulnerability' as the basis for allocating adaptation finance. These studies have argued that poverty indicators are the best indicators of vulnerability and should be taken into account when designing an equitable climate finance allocation framework (Ferreira, 2017).

\section{The method}

To illustrate the potential implication of an equity driven GCF allocation policy on the PSIDS, this article focuses specifically on the ring fenced provision of the GCF adaptation finance. The GCF allocates 50 percent of GCF finance to 
adaptation and then splits that into two equal portions: LDCs, SIDS and African States, and the remaining developing countries (of UNFCCC non-Annex I) creating an impression of special treatment for particularly vulnerable countries.

Using the equality and the prioritarianism principle as the basis for allocation, this study then formulates relevant allocation indicators to highlight the possible futures of GCF adaptation finance for PSIDS post-2020, when the GCF is intending to be mobilised towards US $\$ 100$ billion per annum. This paper recognises that allocation decisions are complex, value laden and have a political dimension (Barr, Frankhauser et al., 2010), thus its aim is to merely highlight how equitybased GCF allocation decisions for adaptation finance could be significant (or not) in relation to the PSIDS precarious situation.

- The analysis was conducted assuming five important caveats:

- The US\$100 billion goal each year by 2020 has been achieved;

- The GCF is the primary vehicle of shifting these finances;

- The ring-fenced US\$25 billion is ready to be allocated post-2020;

- All countries are able to submit GCF-compliant applications greater than the overall GCF limit requiring GCF to determine allocation;

- A total of 97 countries are eligible to access the special funding provision of the GCF. ${ }^{3}$

\section{Results}

Pacific Small Island Developing States' experience can be compared with other identified ring-fenced groups in relation to the four allocation criteria (Figure 1). It is also important to note that this study by no mean proposes that the PSIDS should actually receive the amount derived from these allocation scenarios; it rather wants to highlight the unpredictability of flows in light of no concrete and clear allocation principles.

From the onset (Figure 1), it is clear that the four allocation bases will significantly affect the PSIDS and the wider SIDS. While the allocation amount due to the LDCs and the African states also varies, the amount that these countries would receive under the four allocation basis ranges well above the US\$257 million mark (i.e. the amount a country can receive if a per country criteria is used). This seems to suggest that LDCs and African states are relatively better off compared with PSIDS and SIDS irrespective of the allocation basis used, as the possibilities of large scale and predictable finance is highly certain in these countries.

When compared to the wider SIDSs grouping, the sensitivity of the PSIDS to the allocation criteria is quite evident. The wider SIDS grouping receives an average of US\$2 26 million if allocation were to be made on the basis of population, land area and weighted vulnerability. On the other hand the PSIDS exhibit 


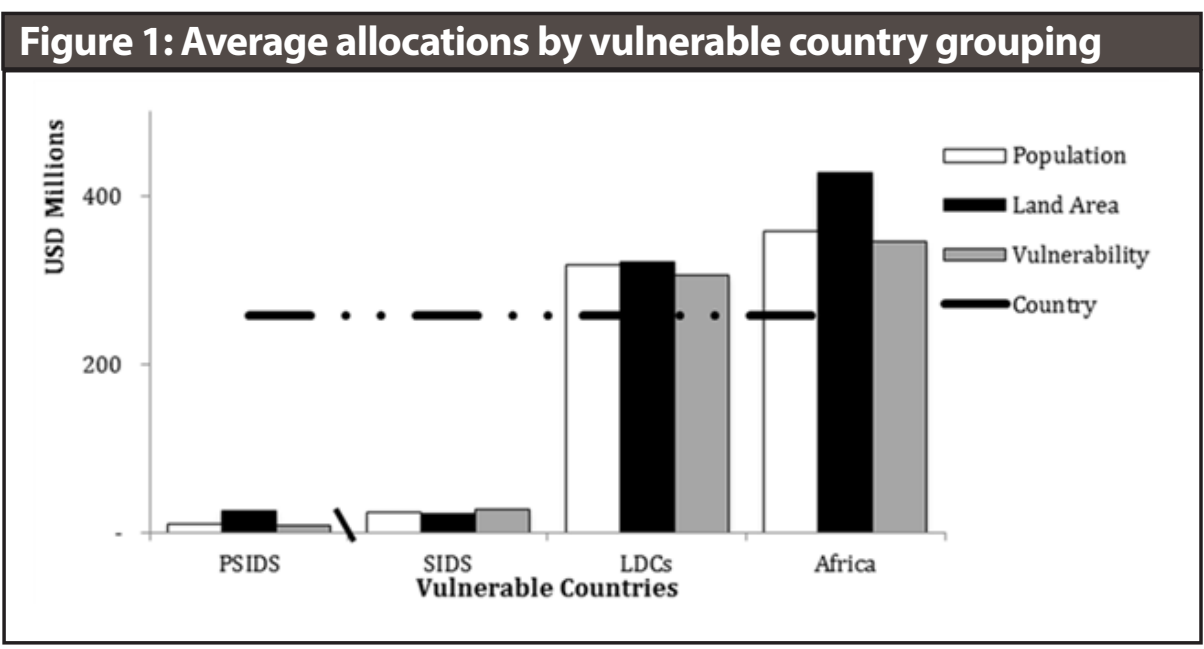

a significant degree of variation in the finance flows when allocation is done on the same three bases. The PSIDS average allocation land area is US\$24 million. This amount decreases by 57 percent if allocation is done on the basis of population and 65 percent if allocation is done on the basis of weighted vulnerability. It is important to also note that the PSIDS overall data is heavily skewed by Papua New Guinea.

The ratio of finances when using the three allocation bases increases significantly for PSIDS and the wider SIDS grouping if allocation is done on a per country basis. For SIDS, the per country allocation amount is on average 10 times higher if allocation is made on the basis of population, total land area and weighted vulnerability. On the other hand, the range of increase varies significantly for PSIDS with the per country basis allocation being 23 times more when compared to the amount of the population criteria, 10 times more when compared with the total land area criteria and 29 times more when compared with weighted vulnerability.

At the regional level, the impact of the four allocation criteria within the PSIDS is also quite significant across countries and allocation criteria (Figure 2). Within the PSIDS, if the GCF allocations were made on the basis of population, those PSIDS categorised as Pacific Smaller Island States (PSIS) ${ }^{4}$ would be the most disadvantaged as they only account for 0.03 percent of the Pacific's population. Niue would be most deprived PSIDS if allocations were to be done on a population basis, because its total population is less than 2000. Timor-Leste, Fiji, Solomon and, to some extent, Vanuatu would experience small but significant climate finance flow due to their high population. PNG, the most populous PSIDS ( $\sim 4$ percent of Pacific population), stands to gain the most adaptation finance in the region.

Papua New Guinea would also benefit the most should the GCF decide to allocate adaptation finance on the basis of land area as it accounts for more than 85 percent of the total land area in the Pacific. While other larger PSIDS such as 
Timor-Leste, Fiji, Solomon and Vanuatu, might also receive significant inflows of adaptation finance, the difference in the ratio between the amounts they receive with that of PNG under such allocation is quite significant ( 25 times). The PSIS whose combined land area only accounts for 0.01 percent of the total land area in the Pacific would be the most penalised under this allocation criterion. Moreover, the ratio of the aggregated allocation amount of PSIS when compared to that of other bigger PSIDS is also quite substantial. Larger PSIDS could receive up to 28 times more adaptation finance under such allocations when compared with PSIS. This difference increases exponentially when compared with that of PNG's allocations.

The impact of a possible allocation based on weighted vulnerability significantly varies among PSIDS when compared against their possible allocations under the population and total land area criterion. Under these terms, Fiji, FSM, Samoa and Kiribati would each stand to receive an increase of about 200 percent in adaptation finance when compared with the amount they could possibly receive from the population and land area allocation criteria, while the magnitude of the increase in Tonga would be 0.7 percent.

For the remaining PSIDS, allocation using weighted vulnerability would be less when compared with the population and the land area allocations. The most notable PSIDS where the weighted vulnerability allocation might result in reduced adaptation flows would be PNG, Solomon and Vanuatu (Figure 2). PNG seems to be the most sensitive PSIDS under this allocation criterion as its adaptation finance could be reduced by 84 percent when compared against the total land area and a 50 percent reduction when compared against the population allocation criteria. However, PNG's position would still be relatively better off under the weighted vulnerability criterion when compared across the wider PSIDS.

\section{Figure 2: PSIDS share if GCF ring-fenced}

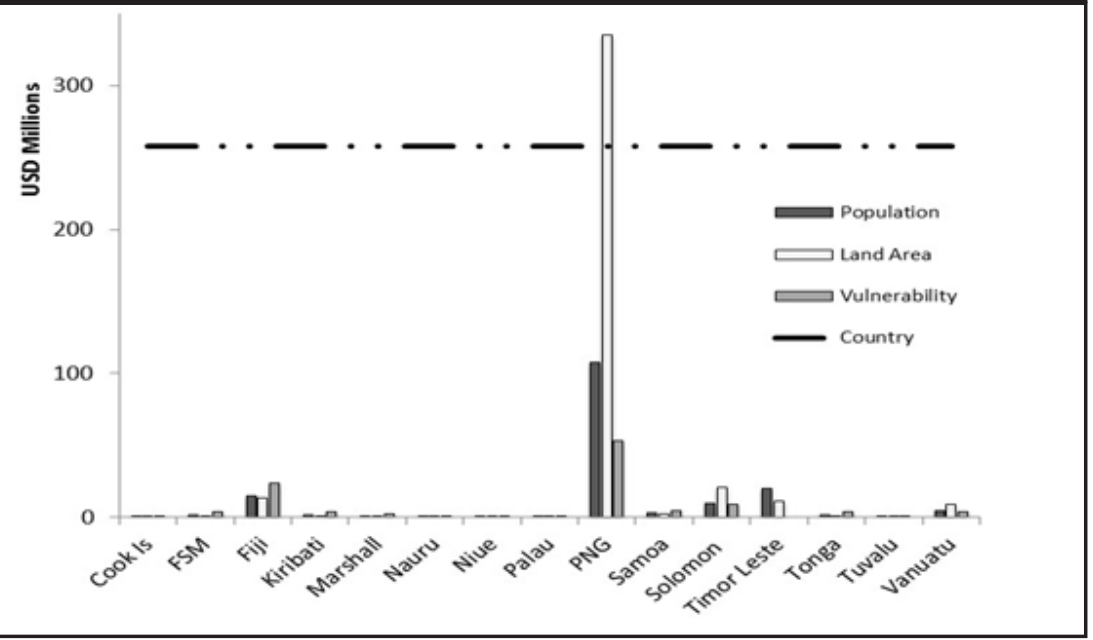

Note: Allocation by population, land area, weighted vulnerability and per country basis. 
The per country allocation criteria would be a definite game-changer for all the PSIDS. When compared with the other three allocation criteria, all the PSIDS stand to gain significant flow of climate finance with an allocation of US\$257 million per country. With the exception of the land area allocation to PNG, the difference between the per country allocation to that of population and weighted vulnerability would be quite significant across PSIDS. For example, Fiji (the second best positioned country behind PNG) would gain 17 times the amount of climate finance if allocations were to be done by a per country basis rather than population, 19 times when compared with allocation by land area and 10 times when compared to weighted vulnerability allocations. These ratios are much higher for the remaining PSIDS, especially for PSIS.

Figure 2 clearly depicts a high degree of climate finance flow variation to each PSIDS under each allocation criteria. It indicates the high sensitivity level of the PSIDS to the possible allocation criteria, which are done on the basis of population, land-area, weighted vulnerability and a per country basis. While PNG, Fiji, Solomon, Timor-Lester and Vanuatu are in a much better position to leverage these allocation criteria, the amount they could receive however, varies significantly depending on the allocation criteria used. Allocations to PSIS are significantly less when compared to other PSIDS, but they could receive large and predictable scale finance if allocation were done on a per country basis.

\section{The effect of GCF finances on existing finance flows}

The impact of the GCF on the existing scale of PSIDS adaptation finance flows was also examined using the 2016 Organization for Economic Co-operation and Development (OECD) data. The OECD database comprehensively tracked the climate finance flow to all developing countries. In computing the effect, the OECD adaptation flow was calculated as a ratio of the finance figure derived from this study's post-2020 allocation criteria. Ratios $1>$ indicate that the GCF allocations will have an impact on current level of financing. While the 2016 flows are not fully comparable with the GCF 2020 flow prediction, the aim is to try and identify the significance of the GCF instrument compared with existing climate finance targeted at adaptation, rather than making any precise comparisons.

If the GCF allocation is done by population, the existing adaptation for 80 percent of PSIDS does not surpass the ratio of 1, suggesting that the level of finance that these PSIDS will receive, might be no greater than what they already received as adaptation finance in 2016 (Figure 3). Only three PSIDS-PNG, Fiji and the Marshall Islands - are poised to experience an increase of more than 100 percent in existing finance. PNG stands to gain more than five times its existing adaptation finance if allocation is done on the basis of population. Existing adaptation finance for PNG would increase 16 times if allocation is done on a total land area basis. 


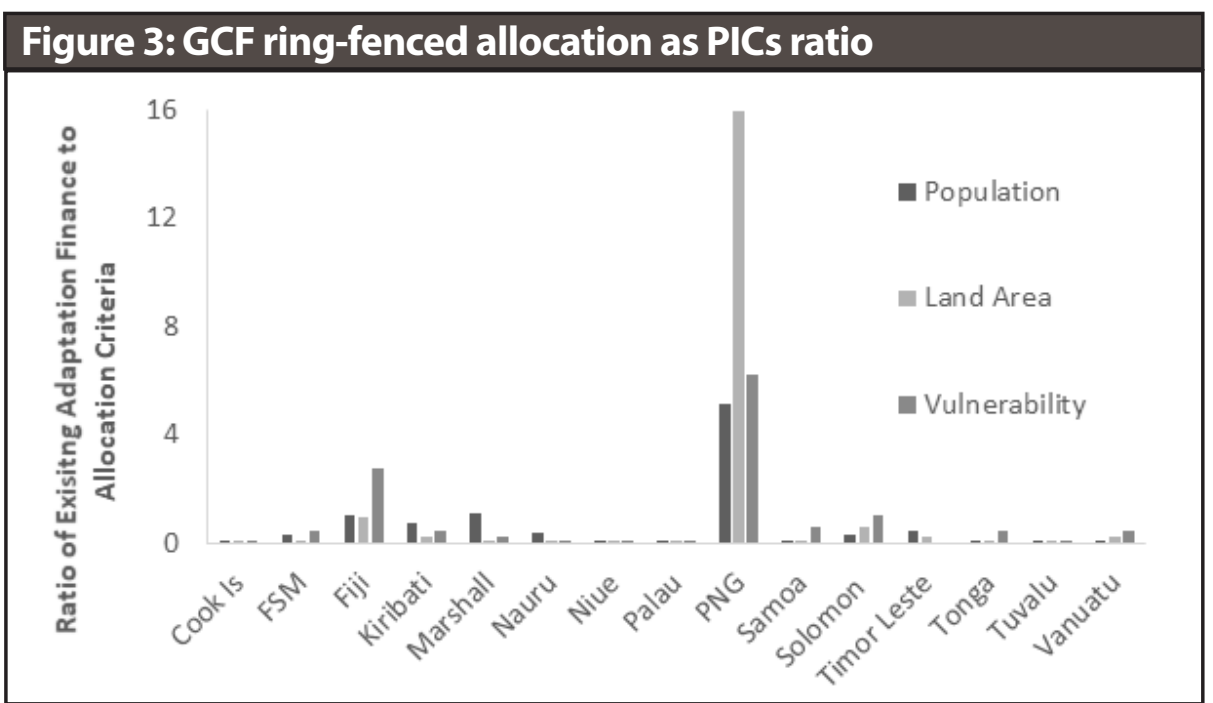

Note: A ratio of the PICs existing adaptation flow.

In terms of weighted vulnerability criteria, PNG, Fiji and Solomon Islands' existing adaptation finance increases by more than 100 percent. PNG will benefit the most among the PSIDS as its existing adaptation finance increases more than six times. FSM, Samoa, Marshall, Kiribati, Tonga and Vanuatu are likely to also experience an increase in their adaptation finance. The PSIDS did not experience a significant increase in their existing adaptation finance, which could be largely attributed to the minimal amount of adaptation finance they have been receiving and their small population base.

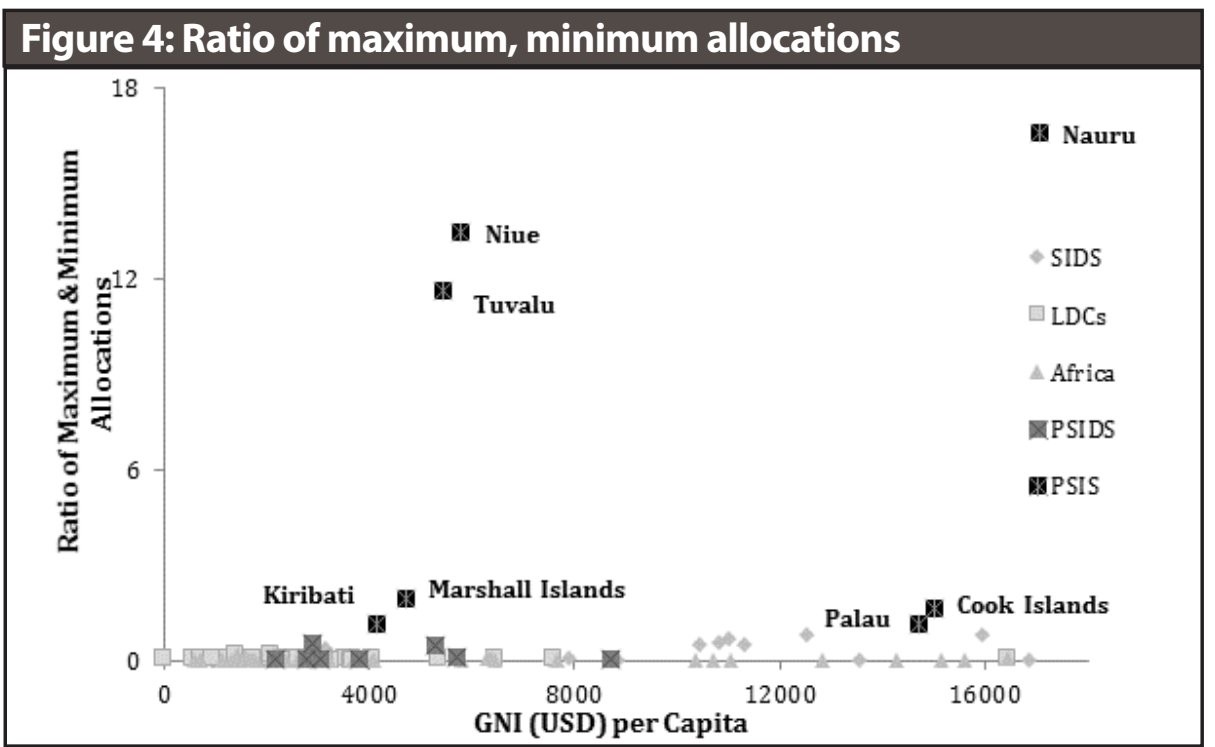

Note: Allocations across the GNI of vulnerable countries. 
On a per country allocation, the existing adaptation finance across most of the PSIDS increases significantly. The PSIS existing climate finances would increase significantly under this allocation criteria; for Nauru this increase is projected to be 600 times greater. For non PSIS, the degree of funding increase would also be significant 'as on average' the existing climate finance would increase 10 times on a per country basis.

The effects of the proposed allocation criteria for particularly vulnerable countries' development are summarised in (Figure 4). To highlight the sensitivity of the four allocation criteria to a country's development status, this study calculated the maximum as well as the minimum allocation across the allocation criteria and then computed the ratio. The ratio was then graphed against the country's 2016 gross national income (GNI) provided by the World Bank. The potential financial flows (Figure 4) are more stable across the LDCs and the African States. This seems to suggest that, even though LDCs and most of the African States are fairly poor, the potential amount that they stood to gain from any potential GCF allocation criteria would be more predictable compared to the SIDS. The data also suggest that PSIDS are more sensitive to any GCF allocation criteria despite their relatively affluent economies. PSIS are most sensitive to potential allocation criteria of the GCF. PSIDS high reliance on external support suggests that the GCF allocation criteria really matter in their development context and this dependence is even more critical in the context of PSIS. The potential of the GCF to support adaptation endeavours is thus much more uncertain for PSIS.

\section{Discussion}

As the GCF mobilises towards 2020, once countries have established access channels and become conversant in the access process, the GCF is likely to be oversubscribed and will need to address allocation issues. The analyses highlighted above are some key indicative scenarios, based on the equity principle to help elaborate the significance of potential future GCF adaptation flows to PSIDS.

For the GCF, finding equitable and fair criteria by which to allocate adaptation finance in a manner that will satisfy all the particularly vulnerable countries will be difficult. At the international level, equitable criteria based on the prioritarianism principle will favour larger, populous LDCs and African States relative to the SIDS. This trend is also reflected at the regional level, where the finance allocations are also skewed towards more populous and bigger PSIDS. Only the equality principle seems to guarantee that predictable adaptation finance will flow to all PSIDS.

The analyses also identify PSIDS as being very sensitive to any allocation criteria by the GCF, which increases the uncertainty of predictable climate finance flow. Depending on the allocation criteria adopted by the GCF, the existing 
climate finance flow to PSIDS can be significantly scaled-up, or can remain largely unchanged; this is likely to have serious implications on their resilience development pathways.

Accessing the GCF ring-fenced adaptation fund is further complicated because the 15 PSIDS will still have to compete with 84 other countries. In a competitive funding environment, PSIDS are more likely to be under-funded because the existing process of the GCF emphasises the need for 'paradigm shift-oriented projects' (GCF, 2018a). This means that the GCF will prioritise the quality of the funding proposal over a country's special circumstances. With chronic shortages of local specialists who are competent in writing and designing quality funding proposals, PSIDS will struggle to compete for GCF funding.

\section{Conclusion}

This study supports the growing voice of concern that the GCF needs to do more for developing countries that are particularly vulnerable to climate change. The critical question this study raises is in relation to post-2020 funding allocation of the GCF, which has received very little attention in the public discourse. There is a critical need to initiate frank and open discussion on the future allocation policy of the GCF, as many developing countries are currently prioritising national accreditation, but paying little attention to post-2020 allocation.

The Pacific Small Island Developing States stand out as being extremely sensitive to potential shifts in GCF post-2020 allocation. Apart from the equality principle, any equitable allocation criterion that promotes the prioritarianism principle seems to indicate that the access to predictable finance promises of the GCF is highly uncertain. While strengthening institutional capacities will benefit PSIDS in pursuing direct access to the GCF, the broad allocation policy of the GCF and its competitive funding-oriented criteria raise legitimate questions about whether pursuing national accreditation is worthwhile for PSIDS, especially the PSIS.

To reduce the uncertainty associated with the post-2020 GCF climate finance flows, this article suggests that the GCF needs to consider a uniform funding floor per country within the GCF ring-fenced provision, in order to ensure a predictable resourcing pathway for the small and the particularly vulnerable countries.

To conclude, there is an urgent need for the media community in the Pacific to advocate more effectively for climate change issues in the region, in particular in relation to climate finance. The Pacific media must do more to provoke discussions in all aspects of climate change, especially those future issues that can have long term implications. As Robie argues:

We are running out of time... [and] news media itself is not terribly good when it comes to long-term issues. It tends to respond to immediate issues and consequences. It lacks the attention span for longer term challenges. (Asia Pacific media must 'empower people', 2018) 
The GCF future allocation policy is a critical long term issue that is imperative to discuss publicly because further delays will only increase the probability that the urgent needs of some PSIDS will be ignored.

\section{Notes}

1. Accreditation refers to the evaluation process that international, regional, and national institutions have to go through if they want to directly access the GCF. To be accredited, an institution has to meet the robust standards required by the GCF.

2. From 2020 to 2025 , the goal is to mobilise US $\$ 100$ billion of climate finance each year. A new climate finance goal is expected to be determined in 2025 .

3 . Ninety seven developing countries who are parties to the UNFCCC fit the requirements of the special ring-fenced portion of the GCF adaptation finance.

4. This grouping is exclusive to six Pacific Smaller Island States (PSIS) — Cook Islands, Nauru, Niue, Palau, Republic of the Marshall Islands and Tuvalu. These islands are made up of low-lying atolls.

\section{References}

Arkin, F. (2018). DevExplains: Green Climate Funds. Retrieved on May 1, 2018, from www.devex.com/news/devexplains-green-climate-funds-91802

Asia Pacific media must 'empower people' on climate action, says PMC (2018, March 26). Asia Pacific Report-Pacific Media Watch 10122. Retrieved on May 1, 2018, from https://asiapacificreport.nz/2018/03/26/asia-pacific-media-must-empower-people-onclimate-action-says-pmc/

Atteridge, A., \& Canales, N. (2017). Climate finance in the Pacific: An overview of flows to the region's Small Island Developing States. Working Paper 2014-04. Stockholm Environment Institute. Stockholm. Retrieved on March 1, 2017, from www.seiinternational.org/publications?pid $=3083$

Azevedo, L. (2017). Green Climate Fund + climate investment funds = global finance architecture. Retrieved on April 1, 2018, from www.afdb.org/en/blogs/a-race-against-time/ post/green-climate-fund-climate-investment-funds-global-finance-architecture-17508/

Barnard, S., Nakhooda, S., Caravani, A., \& Schalatek, L. (2015). Climate Finance Regional Briefing: Asia Climate Finance Fundamentals. London: ODI. 1-4.

Barnett, J., Lambert, S., \& Fry, I. (2008). The hazards of indicators: Insights from the environmental vulnerability index. Annals of the Association of American Geographers, 98(1), 102-119.

Barr, R., Frankhauser, S., \& Hamilton, K. (2010). Adaptation investments: a resource allocation framework. Mitigation and Adaptation Strategies for Global Change, 15(8), 843-858. doi 10.1007/s11027-010-9242-1

Countries pledge \$9.3bn for Green Climate Fund (2014, November 20). The Guardian/ Agence France-Presse. Retrieved April 1, 2018, from www.theguardian.com/environment/2014/nov/20/countries-pledge-93bn-for-green-climate-fund

Dirix, J., Peeters, W., \& Sterckx, S.(2012). Equal per capita entitlements to greenhouse gas emissions: a justice based-critique. In Climate Change and Sustainable Development (pp. 121-127). Wageningen Academic Publishers.

Dreher, T., \& Voyer, M. (2015). Climate refugees or migrants? Contesting media frames 
on climate justice in the Pacific. Environmental Communication, 9(1), 58-76. doi $10.1080 / 17524032.2014 .932818$

Durand, A., Schalatek, L., \&Watson, C. (2015). Climate finance briefing: Small Island Developing States. Climate finance Fundamentals 12. Climate Finance Updates. Heinrich Boll Stiftung. 1-4.

Eisenack, K., \& Stecker, R. (2012). A framework for analyzing climate change adaptations as actions. Mitigation and Adaptation Strategies for Global Change, 17(3), 243-260. doi: 10.1007/s10027-001-9323-9

Ferreira, P.G. (2017). Equitable allocation of climate adaptation finance considering income levels alongside vulnerability. CIGI Papers: No. 152. Center for International Governance Innovation. 1-28.

Friends of the Earth. (2014). Green Climate Fund. Retrieved on May 1, 2018 from https:// foe.org/projects/green-climate-fund/

Füssel, H-M., Hallegate, S., \& Reder, M. (2012). International adaptation funding. In Edenhofer O., Wallacher J., Lotze-Campen H., Reder M., Knopf, B., Müller J. (Eds.), Climate Change, Justice and Sustainability. Springer, Dordrecht. doi:10.1007/978-94-007-4540-7 29

Grasso, M. (2010). An ethical approach to climate adaptation finance. Global Environmental Change, 20(1), 74-81. doi: 10.1016/j.gloenvcha.2009.10.006

GCF (2018a). Empowering countries. Retrieved on April 11, 2018, from www.greenclimate.fund/how-we-work/empowering-countries.

GCF. (2018b). Report of the independent evaluation of the readiness and preparatory support programme. GCF/B.21/28: pp 1-555.

GCF. (2017). GCF perspectives - Ambassador Aliioaiga Feturi Elisaia of Samoa. Retrieved on May 1, 2018, from www.greenclimate.fund/-/gcf-perspectives-ambassadoraliioaiga-feturi-elisaia-of-samoa

GCF. (2014). Policies and procedures for the initial allocation of fund resources. GCF/B.06/05 Retrieved in February, from www.greenclimate.fund/documents/20182/24940/ GCF_B.06_05_Policies_and_Procedures_for_the_Initial_Allocation_of_Fund_Re-

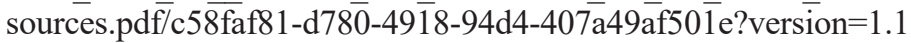

Harvey, C. (2014). Countries are donating billions to a global fund-Here's what it's for. Retrieved on April 30, 2018, from www.businessinsider.com/what-is-the-greenclimate-fund-2014-12.

IPCC. (2018). Global warming of 1.50C: An IPCC special report of the impacts of global warming of $1.50 \mathrm{C}$ above pre-industrial levels and related global greenhouse gas emission pathways, in the context of strengthening the global response to the threat of climate change, sustainable development, and efforts to eradicate poverty. Summary for policy makers. IPCC SR1.5: pp. 1-34.

Klein, R. J., \& Möhner, A. (2011). The political dimension of vulnerability: Implications for the Green Climate Fund. IDS Bulletin, 42(3), 15-22. doi: 10.1111/j.17595436.2011.00218.x

Kumar, R. (2017). Workshop on Green Climate Fund. Retrieved on April 1, 2018, from www.cookislandsnews.com/item/66392-workshop-on-green-climate-fund

Maclellan, N. (2011). Turning the tide: improving access to climate financing in the Pacific Islands. Retrieved on March 10, 2017 from www.lowyinstitute.org/publications/turning-tide-improving-access-climate-financing-pacific-islands

Maclellan, N., \& Meads, S. (2016). After Paris; climate finance in the Pacific islands. Auckland, NZ: Oxfam Research Report.

Maggioni, E. (2010). Justice implications of adaptation to Climate Change and its governance. Retrieved on December 5, 2017, from http://www.diss.fu-berlin.de/docs/servlets/ 
MCRFileNodeServlet/FUDOCS_derivate_000000001614/Maggioni_Justice_Implications_of_Adaptation_to_Climate_Change_and_its_Governance.pdf

Müller, B. (2013). The allocation of (ädaptation) resources lessons from fiscal transfer mechanisms. Retrieved on March 10, 2017, from www.oxfordenergy.org/publications/the-allocation-of-adaptation-resources/

Paavola, J. \& Adger, W.N. (2006). Fair adaptation to climate change. Ecological Economics, 56(4), 594-609. doi: 10.1016/j.ecolecon.2005.03.015

Persson, A. \& Remling, E. (2014). Equity and efficiency in adaptation finance: initial experiences of the Adaptation Fund. Climate Policy, 14(4), 488-506. doi: 10.1080/14693062.2013.879514

Rawls, J. (1958). Justice as fairness. The Philosphical Review, 67(2), 164-194. doi: $10.2307 / 2182612$

Robie, D., \& Chand, S. (2017). Bearing Witness 2016: A Fiji climate change journalism case study. Pacific Journalism Review: Te Koakoa, 23(1), 186-205. doi: 10.24135/pjr.v23i1.257

Rowling, M. (2012). New UN Climate Fund must work for the Poor-NGOs. Retrieved April 30, 2018, from http://wedo.org/new-un-climate-fund-must-work-for-the-poor-ngos/

Sokona, Y., \& Denton, F. (2001). Climate change impacts: can Africa cope with the challenges? Climate Policy, 1(1), 117-123. doi: 10.3763/cpol.2001.0110

Samuwai, J., \& Hills, J.M. (2018). Assessing climate finance readiness in the Asia-Pacific region. Sustainability, 10:1192, 1-18. https://doi.org/10.3390/su10041192

Stadelmann, M., Persson, A., Ratajczak-Juszzko, I., \& Michaelowa, A. (2014). Equity and cost-effectiveness of multilateral adaptation finance: are they friends or foes? International Environmental Agreements: Politics, Law and Economics, 14(2), 101 120. doi: 10.1007/s10784-013-9206-5

The World Bank. (2017). The World Bank in Pacific islands. Retrieved on September 15, 2017, from www.worldbank.org/en/country/pacificislands

UNDP. (2018). Engaging the Green Climate Fund - GCF Readiness Programme Report. New York, NY: UNDP: pp. 1-60.

Wing, T. (2017). Submerging paradise: Climate change in the Pacific Islands. Retrieved February 26, 2018, from http://climate.org/submerging-paradise-climate-change-inthe-pacific-islands/.

Wolff, J. (1998). Fairness, respect, and the egalitarian ethos. Philosophy \& Public Affairs 27(2), 97-122.

Jale Samuwai is a doctoral candidate of the Pacific Centre for Environment and Sustainable Development (PaCE-SD) at the University of the South Pacific.

jalecuruki5@gmail.com

Dr Jeremy Hills is a professor at USP. He is a finance and Green Climate Fund readiness specialist.

jeremy.hills@usp.ac.fj 